\title{
HUBUNGAN RIWAYAT PERSALINAN DAN PARITAS DENGAN PERSALINAN PREMATUR PADA IBU BERSALIN DI RUANG KEBIDANAN RS TK IV ZAINUL ARIFIN 02.07.01
}

\section{The Relationship between History of Childbirth and Parity with Preterm Labor in Mothers in Labor in Midwifery Room of Zainul Arifin TK IV 02.07.01 Hospital}

\author{
Waytherlis Apriani ${ }^{1}$, Destika Nurjannah ${ }^{1}$ \\ ${ }^{1}$ Program Studi Sarjana Terapan Kebidanan STIKES Tri Mandiri Sakti Bengkulu \\ Email: iterapriani12@gmail.com
}

\author{
ARTICLE HISTORY \\ Received [10 Agustus 2020] \\ Revised [11 Agustus 2020] \\ Accepted [30 Agustus 2020]
}

KATA KUNCI:

Ibu bersalin, paritas, persalinan prematur, riwayat persalinan

\section{KEYWORDS:}

history of childbirth, mothers in labor, parity, preterm labor

\section{ABSTRAK}

Dampak persalinan preterm adalah kematian perinatal, respiratory distress syndrome, perdarahan intra/periventrikular, necrotizing entero cilitis, displasi bronko-pulmonar, sepsis, dan paten duktus arteriosus pada bayi. Penelitian ini bertujuan untuk mengetahui hubungan riwayat persalian dan paritas dengan persalian prematur pada ibu bersalin di Ruang Kebidanan RS TK IV Zainul Arifin 02.07.01 Kota Bengkulu. Penelitian ini menggunakan desain Case Control. Populasi dalam penelitian ini seluruh ibu bersalin di Ruang Kebidanan RS TK IV Zainul Arifin 02.07.01 Kota Bengkulu tahun 2017. Pengambilan sampel kasus menggunakan teknik Total Sampling yaitu sebanyak 59 ibu bersalin dan sampel kontrol menggunakan teknik Systematic Random Sampling sebanyak 59 ibu bersalin. Data dianalisis secara univariat dan bivariat. Analisis bivariat menggunakan uji statistik Chi-Square. Hasil penelitian didapatkan bahwa terdapat 59 ibu bersalin (50\%) yang mengalami persalinan prematur, 75 ibu bersalin $(63,6 \%)$ yang tidak pernah mengalami persalinan prematur, 81 ibu bersalin $(68,6 \%)$ yang memiliki paritas multipara. Terdapat hubungan yang signifikan antara riwayat persalinan dengan persalinan prematur dengan kategori hubungan sedang. Terdapat hubungan yang signifikan antara paritas dengan persalinan prematur dengan kategori hubungan lemah. Diharapkan tenaga kesehatan dapat memberikan konseling, informasi dan edukasi untuk mencegah persalinan prematur.

\section{ABSTRACT}

The effects of preterm labor are perinatal mortality, respiratory distress syndrome, intra/periventricular hemorrhage, necrotizing entero cilitis, bronco-pulmonary dysplasia, sepsis, and patent ductus arteriosus in infants. This study aimed to determine the relationship between history of childbirth and parity with preterm labor in mothers in labor in Midwifery Room of TK IV Zainul Arifin 02.07.01 Hospital, Bengkulu City. This study used a Case Control design. The population in this study were all mothers giving birth in Midwifery Room TK IV Zainul Arifin Hospital 02.07.01 Bengkulu City in 2017. Case samples were taken using Total Sampling technique, namely 59 mothers and control samples using Systematic Random Sampling technique of 59 mothers. Data were analyzed by univariate and bivariate. Bivariate analysis used Chi-Square statistical test. The results showed that there were 59 women who gave birth (50\%) who had premature labor, 75 women who gave birth $(63.6 \%)$ who had never experienced preterm labor, 81 mothers who gave birth (68.6\%) who had multiparity parity. There was a significant relationship between history of childbirth and preterm labor with a moderate relationship category. There was a significant relationship between parity and preterm delivery with a weak relationship category. It was hoped that health workers can provide counseling, information and education to prevent preterm labor. 


\section{Pendahuluan}

Menurut laporan World Health Organization (WHO) diperkirakan jumlah kelahiran prematur diperkirakan 15 juta setiap tahun. Hampir satu juta anak meninggal setiap tahun akibat komplikasi kelahiran prematur di mana lebih dari $60,0 \%$ kelahiran prematur terjadi di Afrika dan Asia Selatan. Sementara itu, negara-negara berpenghasilan rendah, rata-rata terjadi $12,0 \%$ bayi lahir prematur, sedangkan di negara-negara berpenghasilan tinggi hanya 9\% (Sulistiarini \& Berliana, 2016).

Di Provinsi Bengkulu pada tahun 2015 dari 36.920 bayi, jumlah bayi lahir hidup sebesar 35.824 bayi dan jumlah kematian bayi sebesar 206 kasus. Selain itu tercatat sebanyak 387 bayi lahir dengan berat badan lahir kurang karena persalinan prematur (Dinkes Provinsi Bengkulu, 2016).

Dampak dari persalinan preterm di antaranya adalah kematian perinatal, kelainan jangka pendek maupun jangka panjang pada bayi. Kelainan jangka pendek seperti respiratory distress syndrome, perdarahan intra/periventrikular, necrotizing entero cilitis, displasi bronko-pulmonar, sepsis, dan paten duktus arteriosus (Winkjosastro, 2014).

Hasil penelitian Paembonan, Ansar, \& Arsyad (2013) menunjukkan bahwa riwayat kelahiran preterm merupakan faktor risiko kejadian kelahiran preterm di Rumah Sakit Ibu dan Anak Siti Fatimah Makassar. Ibu dengan hamil dengan riwayat kelahiran preterm memiliki risiko mengalami persalinan preterm 20 kali lebih tinggi. Hasil penelitian Wahyuni \& Rohani (2017) menunjukkan bahwa terdapat hubungan antara paritas dengan persalinan prematur di RSUD dr. Abdul Moeloek. Hasil penelitian Karolin \& Widiastuti (2019) juga menunjukkan bahwa ada hubungan antara paritas dengan persalinan preterm di RS Muhammadiyah Taman Puring Kebayoran Baru Jakarta Selatan.

Berdasarkan data yang diperoleh di ruang kebidanan RS TK IV Zainul Arifin 02.07.01 Kota Bengkulu, didapatkan data jumlah ibu dengan kasus persalinan prematur pada bulan Januari-Maret 2018 mencapai 21 orang yang terdiri dari 17 orang dengan paritas beresiko yang memiliki riwayat persalinan prematur sebelumnya yaitu multipara 13 orang dan 4 orang grandemultipara. Ada 4 orang ibu lainnya dengan paritas primipara dan tidak memiliki riwayat persalinan prematur sebelumnya tetapi memiliki penyakit pada saat kehamilan seperti preeklamsia-eklamsia.

Rumusan masalah dalam penelitian ini adalah "Apakah ada hubungan riwayat persalinan dan paritas dengan persalinan prematur pada ibu bersalin di ruang kebidanan RS TK IV Zainul Arifin 02.07.01 Kota Bengkulu?". Tujuan penelitian ini adalah untuk mempelajari hubungan antara riwayat persalinan dan paritas dengan persalinan prematur pada ibu bersalin di Ruang Kebidanan RS TK IV Zainul Arifin 02.07.01 Kota Bengkulu.

\section{Metode Penelitian}

Lokasi penelitian di Ruang Kebidanan RS TK IV Zainul Arifin 02.07.01 Kota Bengkulu pada bulan Juni-Juli 2018. Jenis penelitian adalah Survey Analitik dengan desain Case Control. Populasi dalam penelitian seluruh ibu bersalin di Ruang Kebidanan RS TK IV Zainul Arifin 02.07.01 Kota Bengkulu tahun 2017. Pengambilan sampel kasus menggunakan teknik Total Sampling yaitu sebanyak 59 ibu bersalin dan sampel kontrol menggunakan teknik Systematic Random Sampling sebanyak 59 ibu bersalin. Data dianalisis secara univariat dan bivariate. Analisis bivariat menggunakan uji statistik Chi-Square.

\section{Hasil Penelitian}

\section{Analisis Univariat}

Analisis univariat bertujuan untuk mengetahui distribusi frekuensi persalinan premature, riwayat prematur, dan paritas pada ibu bersalin di Ruang Kebidanan RS TK IV Zainul Arifin 02.07.01 Kota Bengkulu. Hasil analisis adalah sebagai berikut : 
Tabel 1.

Distribusi Frekuensi Persalinan Prematur pada Ibu Bersalin di Ruang Kebidanan RS TK IV Zainul Arifin 02.07.01 Kota Bengkulu

\begin{tabular}{clcc}
\hline No. & Persalinan Prematur & Frekuensi & Persentase $(\%)$ \\
\hline 1 & Ya & 59 & 50,0 \\
2 & Tidak & 59 & 50,0 \\
\hline & Jumlah & 118 & 100,0 \\
\hline
\end{tabular}

Berdasarkan Tabel 1 di atas, dari 118 ibu bersalin di Ruang Kebidanan RS TK IV Zainul Arifin 02.07.01 Kota Bengkulu, terdapat 59 ibu bersalin $(50,0 \%)$ yang mengalami persalinan prematur dan $59 \mathrm{ibu}$ bersalin (50\%) yang tidak mengalami persalinan prematur.

Tabel 2.

Distribusi Frekuensi Riwayat Prematur pada Ibu Bersalin di Ruang Kebidanan RS TK IV Zainul Arifin 02.07.01 Kota Bengkulu

\begin{tabular}{cccc}
\hline No. & Riwayat Persalinan & Frekuensi & Persentase (\%) \\
\hline 1 & Ya, Pernah & 43 & 36,4 \\
2 & Tidak pernah & 75 & 63,6 \\
\hline & Jumlah & 118 & 100,0 \\
\hline
\end{tabular}

Berdasarkan Tabel 2 dari 118 ibu mengalami persalinan prematur sebelumnya bersalin di Ruang Kebidanan RS TK IV dan 75 ibu bersalin $(63,6 \%)$ tidak pernah Zainul Arifin 02.07.01 Kota Bengkulu, mengalami persalinan prematur sebelumnya. terdapat $43 \mathrm{ibu}$ bersalin $(36,4 \%)$ pernah

Tabel 3.

Distribusi Frekuensi Paritas pada Ibu Bersalin di Ruang Kebidanan RS TK IV Zainul Arifin 02.07.01 Kota Bengkulu

\begin{tabular}{cccc}
\hline No. & Paritas & Frekuensi & Persentase $(\%)$ \\
\hline 1 & Grandemultipara & 37 & 31,4 \\
2 & Multipara & 81 & 68,6 \\
\hline & Jumlah & 118 & 100,0 \\
\hline
\end{tabular}

Berdasarkan hasil penelitian tampak bahwa dari 118 ibu bersalin di Ruang Kebidanan RS TK IV Zainul Arifin 02.07.01 Kota Bengkulu, terdapat $37 \mathrm{ibu}$ bersalin $(31,4 \%)$ memiliki paritas grandemultipara dan 81 ibu bersalin $(68,6 \%)$ memiliki paritas multipara.

\section{Analisis Bivariat}

Analisis bivariat bertujuan untuk mengetahui hubungan antara riwayat prematur dan paritas dengan persalinan prematur pada ibu bersalin di Ruang Kebidanan RS TK IV Zainul Arifin 02.07.01 Kota Bengkulu. Hasil analisis adalah sebagai berikut : 
Tabel 4.

Hubungan Riwayat Persalinan dengan Persalinan Prematur pada Ibu Bersalin di Ruang

Kebidanan RS TK IV Zainul Arifin 02.07.01 Kota Bengkulu

\begin{tabular}{|c|c|c|c|c|c|c|c|c|c|c|}
\hline \multirow{3}{*}{$\begin{array}{l}\text { Riwayat } \\
\text { Persalinan }\end{array}$} & \multicolumn{4}{|c|}{ Persalinan Prematur } & \multirow{2}{*}{\multicolumn{2}{|c|}{ Total }} & \multirow{3}{*}{$\chi^{2}$} & \multirow{3}{*}{$\mathrm{p}$} & \multirow{3}{*}{$\mathrm{C}$} & \multirow{3}{*}{ OR } \\
\hline & \multicolumn{2}{|c|}{$\mathrm{Ya}$} & \multicolumn{2}{|c|}{ Tidak } & & & & & & \\
\hline & $\mathrm{F}$ & $\%$ & $\mathrm{~F}$ & $\%$ & $\mathrm{~F}$ & $\%$ & & & & \\
\hline$\overline{\text { Pernah prematur }}$ & 33 & 76,7 & 10 & 23,2 & 43 & 100,0 & & & & \\
\hline $\begin{array}{l}\text { Tidak pernah } \\
\text { prematur }\end{array}$ & 26 & 34,7 & 49 & 65,3 & 75 & 100,0 & 17,709 & 0,000 & 0,375 & 6,219 \\
\hline Total & 59 & 50,0 & 59 & 50,0 & 118 & 100,0 & & & & \\
\hline
\end{tabular}

Berdasarkan tabel tabulasi silang di atas, dari $43 \mathrm{ibu}$ bersalin dengan riwayat persalinan prematur sebelumnya, terdapat 33 ibu bersalin yang mengalami persalinan prematur dan $10 \mathrm{ibu}$ bersalin tidak persalinan prematur. Dari 75 ibu bersalin yang tidak pernah mengalami riwayat prematur sebelumnya, terdapat 26 ibu bersalin dengan persalinan prematur dan $49 \mathrm{ibu}$ bersalin tidak persalinan prematur. Hasil uji statistik ChiSquare (Continuity Correction) didapatkan nilai $\chi 2=17,709$ dengan $\mathrm{p}=0,000<0,05$ berarti signifikan, maka Ho ditolak dan $\mathrm{Ha}$ diterima. Jadi terdapat hubungan yang signifikan antara riwayat persalinan dengan persalinan prematur pada ibu bersalin di Ruang Kebidanan RS TK IV Zainul Arifin 02.07.01 Kota Bengkulu.

Tabel 5.

Hubungan Paritas dengan Persalinan Prematur pada Ibu Bersalin di Ruang Kebidanan RS TK IV Zainul Arifin 02.07.01 Kota Bengkulu

\begin{tabular}{|c|c|c|c|c|c|c|c|c|c|c|}
\hline \multirow{3}{*}{ Paritas } & \multicolumn{4}{|c|}{ Persalinan Prematur } & \multirow{2}{*}{\multicolumn{2}{|c|}{ Total }} & \multirow{3}{*}{$\chi^{2}$} & \multirow{3}{*}{$\mathrm{p}$} & \multirow{3}{*}{$\mathrm{C}$} & \multirow{3}{*}{ OR } \\
\hline & \multicolumn{2}{|c|}{$\mathrm{Ya}$} & \multicolumn{2}{|c|}{ Tidak } & & & & & & \\
\hline & $\mathrm{F}$ & $\%$ & $\mathrm{~F}$ & $\%$ & $\mathrm{~F}$ & $\%$ & & & & \\
\hline Grandemultipara & 26 & 70,3 & 11 & 29,7 & 37 & 100 & & & & \\
\hline Multipara & 33 & 40,7 & 48 & 59,3 & 81 & 100 & 7,717 & 0,005 & 0,264 & 3,438 \\
\hline Total & 59 & 50,0 & 59 & 50,0 & 118 & 100 & & & & \\
\hline
\end{tabular}

Berdasarkan tabel tabulasi silang di atas tampak bahwa dari 37 ibu bersalin yang memiliki paritas grandemultipara, terdapat 26 ibu bersalin yang mengalami persalinan prematur dan 11 ibu bersalin tidak mengalami persalinan prematur. Dari $81 \mathrm{ibu}$ bersalin yang memiliki paritas mutipara, terdapat $33 \mathrm{ibu}$ bersalin yang mengalami persalinan prematur dan 48 ibu bersalin yang tidak mengalami persalinan prematur. Hasil uji statistik Chi-Square (Continuity Correction) didapatkan nilai $\chi^{2}=7,717$ dengan $\mathrm{p}=0,005<0,05$, berarti signifikan maka Ho ditolak dan Ha diterima. Jadi terdapat hubungan yang signifikan antara paritas dengan persalinan prematur pada ibu bersalin di Ruang Kebidanan RS TK IV Zainul Arifin 02.07.01 Kota Bengkulu.

\section{Pembahasan}

Hasil uji statistik didapat hubungan yang signifikan antara riwayat persalinan dengan persalinan prematur pada ibu bersalin di Ruang Kebidanan RS TK IV Zainul Arifin 02.07.01 Kota Bengkulu dengan kategori hubungan sedang. Hasil penelitian ini sejalan dengan hasil penelitian Paiembonan (2013) yang menunjukkan bahwa riwayat kelahiran preterm merupakan faktor risiko kejadian kelahiran preterm di Rumah Sakit Ibu dan Anak Siti Fatimah Makassar. Ibu dengan hamil dengan riwayat kelahiran preterm 
memiliki risiko mengalami persalinan preterm 20 kali lebih tinggi.

Hasil penelitian ini sejalan dengan teori Varney (2011) yang menyatakan bahwa risiko persalinan prematur berulang bagi wanita yang persalinan pertamanya preterm dapat meningkat tiga kali lipat jika dibandingkan dengan wanita yang persalinan pertamanya mencapai aterm. Riwayat prematur sebelumnya merupakan ibu yang pernah mengalami persalinan prematur sebelumnya pada kehamilan yang terdahulu. Ibu yang tidak dapat melahirkan bayi sampai usia aterm dapat disebabkan karena kandungan/rahim ibu yang lemah atau faktor lain yang belum diketahui jelas penyebabnya. Wanita yang telah mengalami kelahiran prematur pada kehamilan terdahulu memiliki risiko $20,0 \%-40,0 \%$ untuk terulang kembali. Ibu dengan riwayat persalinan prematur sebelumnya lebih beresiko mengalami persalinan prematur 6,2 kali lebih besar jika dibandingkan dengan ibu yang tidak memiliki riwayat persalinan prematur sebelumnya.

Hasil penelitian ini sejalan dengan teori Hacker (2011) yang menyatakan bahwa riwayat prematur sebelumnya merupakan faktor risiko terhadap terjadinya persalinan premature. Hasil penelitian menunjukkan bahwa ibu bersalin multiparitas yang ada riwayat prematur sebelumnya mempunyai peluang 3,022 kali mengalami persalinan prematur jika dibandingkan dengan ibu bersalin multiparitas yang tidak ada riwayat prematur sebelumnya. Hasil penelitian Paiembonan (2013) menunjukkan bahwa riwayat kelahiran preterm merupakan faktor risiko kejadian kelahiran preterm di Rumah Sakit Ibu dan Anak Siti Fatimah Makassar. Ibu hamil yang memiliki riwayat kelahiran preterm memiliki risiko mengalami persalinan preterm 20 kali lebih tinggi jika dibandingkan dengan ibu hamil yang tidak memiliki riwayat kelahiran preterm.

Hasil penelitian ini sesuai dengan teori yang menyatakan kelahiran kurang bulan/prematur telah terjadi pada kelahiran pertama, maka risiko relatif terhadap kelahiran prematur berikutnya adalah 2-4 kali dan akan meningkat bila dua persalinan sebelumnya prematur.

Hasil uji statistik menunjukkan bahwa ada hubungan yang signifikan antara paritas dengan persalinan prematur pada ibu bersalin di ruang kebidanan RS TK IV Zainul Arifin 02.07.01 Kota Bengkulu dengan kategori hubungan lemah. Hasil penelitian ini menunjukkan bahwa paritas menentukan terjadinya persalinan prematur tetapi masih banyak faktor lain seperti, penyakit bawaan ibu, status gizi ibu, usia, dan jarak kehamilan.

Hasil penelitian ini sejalan dengan teori yang dikemukakan oleh Joeharno (2016) bahwa paritas yang grandemultipara akan berdampak pada timbulnya berbagai masalah kesehatan baik bagi ibu maupun janin. Alat-alat reproduksi yang lemah belum siap menerima implantasi dengan baik. Hal ini disebabkan karena adanya kemunduran fungsi fisologis dan reproduksinya secara umum, khususnya pada keadaan endometrium dan korpus uteri sudah mengalami kemunduran fungsi dan berkurangnya vaskularisasi, dan oksigenisasi pada hasil konsepsi kurang maksimal sehingga memicu partus prematur.

Hasil penelitian sejalan dengan hasil penelitian Wahyuni \& Rohani (2017) yang menunjukkan bahwa terdapat hubungan antara paritas dengan persalinan prematur di RSUD dr. Abdul Moeloek. Hasil penelitian Karolin \& Widiastuti (2019) juga menunjukkan bahwa ada hubungan antara paritas, dengan persalinan preterm di RS Muhammadiyah Taman Puring Kebayoran Baru Jakarta Selatan.

\section{Kesimpulan}

1. Terdapat 59 ibu bersalin $(50,0 \%)$ yang mengalami persalinan prematur di Ruang Kebidanan RS TK IV Zainul Arifin 02.07.01 Kota Bengkulu.

2. Terdapat $75 \mathrm{ibu}$ bersalin $(63,6 \%)$ yang tidak pernah mengalami persalinan prematur di Ruang Kebidanan RS TK IV Zainul Arifin 02.07.01 Kota Bengkulu.

3. Terdapat $81 \mathrm{ibu}$ bersalin $(68,6 \%)$ yang memiliki paritas multipara di Ruang 
Kebidanan RS TK IV Zainul Arifin 02.07.01 Kota Bengkulu.

4. Terdapat hubungan yang signifikan antara riwayat persalinan dengan persalinan prematur pada ibu bersalin di Ruang Kebidanan RS TK IV Zainul Arifin 02.07.01 Kota Bengkulu, dengan kategori hubungan sedang.

5. Terdapat hubungan yang signifikan antara paritas dengan persalinan prematur pada ibu bersalin di Ruang Kebidanan RS TK IV Zainul Arifin 02.07.01 Kota Bengkulu, dengan kategori hubungan lemah.

\section{Daftar Pustaka}

Dinkes Provinsi Bengkulu. (2016). Profil Dinas Kesehatan Propinsi Bengkulu 2016. Bengkulu : Dinkes Provinsi Bengkulu.

Hacker, N. (2011). Essensial Obstetri dan Ginekologi. Edisi 2. Jakarta : Hipokrates.

Joeharno, I. (2016). Konsep Dasar Risiko Bahaya Kehamilan Berisiko. Jakarta: Salemba Medika.

Karolin, B. T., \& Widiastuti, I. (2019). Faktor-Faktor yang Berhubungan dengan Kejadian Persalinan Preterm di Rumah Sakit Muhammadiyah Taman Puring Kebayoran Baru Jakarta Selatan Periode Januari - Juni Tahun 2017. Jurnal Ilmu Keperawatan dan Kebidanan, 1 (1). Diunduh dari http://journal.unas.ac.id/health/article/ viewFile/495/389.

Paembonan, N., Ansar, D., \& Arsyad, D. S. (2013). Faktor Risiko Kejadian Kelahiran Prematur di Rumah sakit Ibu dan Anak Siti Fatimah Kota Makassar. Diunduh dari : https://core.ac.uk/download/pdf/2549 4747.pdf.

Sulistiarini, D, \& Berliana, S. M. (2013). Faktor-Faktor yang Mempengaruhi Kelahiran Prematur di Indonesia : Analisis data Riskesdas 2013. Widya Kesehatan dan Lingkungan, 1 (2) : 109-115. Diunduh dari : https://media.neliti.com/media/public ations/36815-ID-faktor-faktor-yangmemengaruhi-kelahiran-prematur-diindonesia-analisis-data-ris.pdf.

Varney, H. 2011. Buku Ajar Asuhan Kebidanan. Edisi 4. Jakarta: EGC.

Wahyuni, R., \& Rohani, S. (2017). Hubungan antara paritas dengan persalinan prematur di RSUD dr. Abdul Moeloek. Aisyah Jurnal Ilmu Kesehatan, 2 (1) : 61-68. Diunduh dari:

https://aisyah.journalpress.id/index.ph p/jika/article/view/RW\%20$\% 20 \mathrm{SR} / 32$.

Winkjosastro. (2014). Ilmu Kebidanan. Jakarta: Yayasan Bina Pustaka. 